\title{
Drone Applications for Supporting Disaster Management
}

\author{
Agoston Restas \\ Institute of Disaster Management, National University of Public Service, Budapest, Hungary \\ Email: Restas.Agoston@uni-nke.hu
}

Received 8 September 2015; accepted 15 October 2015; published 22 October 2015

\begin{abstract}
Introduction: Besides the military and commercial applications of drones, there is no doubt in their efficiency in case of supporting emergency management. This paper evaluates some experiences and describes some initiatives using drones to support disaster management. Method: This paper focuses mainly on operational and tactical drone application in disaster management using a time-scaled separation of the application, like pre-disaster activity, activity immediately after the occurrence of a disaster and the activity after the primary disaster elimination. Paper faces to 5 disasters, like nuclear accidents, dangerous material releases, floods, earthquakes and forest fires. Author gathered international examples and used own experiences in this field. Results and discussion: An earthquake is a rapid escalating disaster, where, many times, there is no other way for a rapid damage assessment than aerial reconnaissance. For special rescue teams, the drone application can help much in a rapid location selection, where enough place remained to survive for victims. Floods are typical for a slow onset disaster. In contrast, managing floods is a very complex and difficult task. It requires continuous monitoring of dykes, flooded and threatened areas. Drone can help managers largely keeping an area under observation. Forest fires are disasters, where the tactical application of drone is already well developed. Drone can be used for fire detection, intervention monitoring and also for post-fire monitoring. In case of nuclear accident or hazardous material leakage drone is also a very effective or can be the only one tool for supporting disaster management.
\end{abstract}

\section{Keywords}

Disaster Management, Flood, Earthquake, Nuclear Accident, Hazardous Material, Forest Fire, UAV, UAS, RPAS, Drone

\section{Introduction}

A disaster is a natural or man-made (or technological) hazard resulting in an event of substantial extent causing significant physical damage or destruction, loss of life, or drastic change to the environment. A disaster can be defined as any tragic event stemming from events such as earthquakes, floods, accidents, fires, or explosions. It is a phenomenon that can cause damage to life and property and destroy the economic, social or cultural life of people. 
The name, "drone” is_-more or less—common name of the unmanned aerial systems; its abbreviation is UAS. In many cases we can find other appearance such as UAV (Unmanned Aerial Vehicle) but in Europe the Remotely Piloted Aircraft Systems (RPAS) is also commonly used name [1]. Author is sure, the name "drone" understandable for everybody however many experts wish to express it more sophisticated with UAV, UAS or RPAS.

There are many way to scale different disasters. Disasters can be scaled from limited to escalated, by the effected area or population, from the eruption to slowly spreading by the time it develops, or in many other ways depending on the condition we take into account. This paper uses namely some disasters such as floods, earthquakes, nuclear accidents and forest fires, however demonstratively expresses that topic is so huge, all presented work is just touching the surface.

Stating the eruption in the center of the disaster's time scale any activity, so logically also all drone applications supporting disaster management can be thematically separated like it can be seen in Figure 1. Before the eruption as a pre-disaster activity drone application can support the prevention or be able to supply the early detection. In case of man-made disasters like a chemical accident during illegal transport the drone road observation belongs to prevention, following a toxic smoke spreading belongs to early detection, while avoiding the an escalated forest fire by drone flight patrol can belong to both prevention and early detection. After the eruption drone can support the management with real time monitoring that means mostly the quick and relevant information regarding the intervention or mitigation. Based on the by drone supplied information the effect of the disaster can be mitigated more effectively and all of relevant information can support making better decision. Finishing main interventions, commonly it means after disaster, drone can support the quick damage assessment and also help recovery. This drone application is titled as post-disaster activity. This application is the closest to the civil life.

Depending on the type of disaster, the affected area, severity, etc. the above activities can be totally different from each other's. The response at erupted nuclear accident requests different drone activity than the slowly escalated flood. Other side drone applications can depend also on the level of managing disaster. At the headquarter management require strategical information but end-users needs information immediately about the situation. Therefore drone applications in managing level can be divided into 3 groups such as strategical, operational and tactical levels.

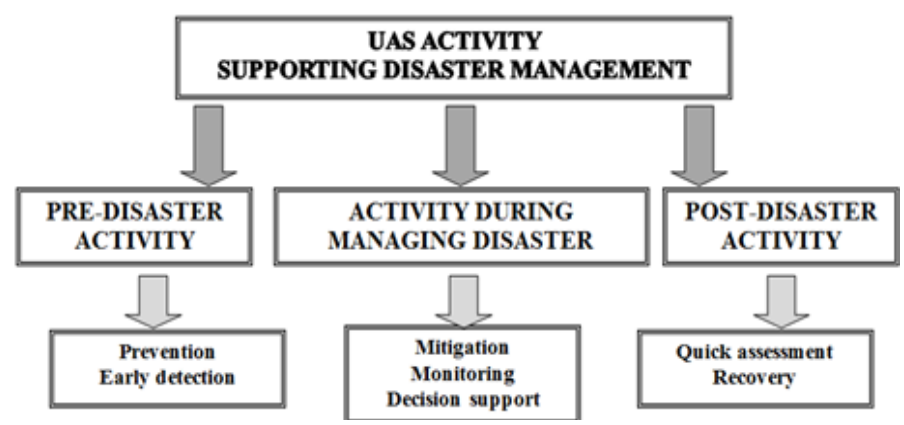

Figure 1. Drone (UAV/UAS/RPAS) activity in time scale of disaster eruption. Source: author.

\section{Spread of Hazardous Materials and Nuclear Accidents}

At accidents involving hazardous materials, the primary task to be solved by drone flights is the early and accurate identification of the direction of the spread of liquids or gaseous materials. This problem is partially solved now with help of the advanced set of equipment disaster management (Disaster Management Mobile Lab). Its features are the relative immobility and 2-dimensional imaging. Through drone flights, three-dimensional images (Figure 2), so-called rheological curves may be obtained in large areas, quickly and objectively. This is obviously able to support the decisions of response controllers much better.

In the intervention phase, the takeoff and landing sites are certainly located farther away from the contaminated area, so the threat of drone pilots is negligible. Examining the human factors, the severity and duration of disaster will be determinant; initially the effects of the rapid takeoff due to time pressure, caused by the hunger 

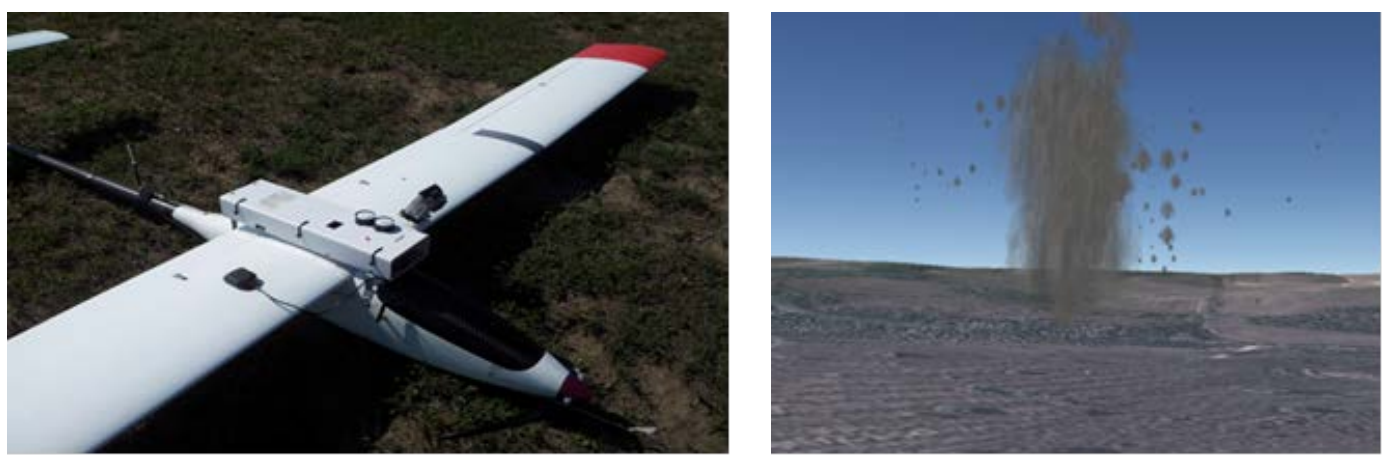

Figure 2. Fix wing drone equipped with chemical sensors (left) and the result of its fly: 3D model of the detected nitrogen-monoxide [2].

for information, on the other hand, the impacts of possible enduring flights are ought be borne in mind. It may be assumed that the search for trapped people may take place, so, drone flights may also become key factors in saving human lives. There may be occasions that this burden is difficult to be withstood by drone pilots; however, the opposite may also occur when it becomes a motivating factor for a successful performance.

After the primary intervention and damage liquidation functions in accidents and disasters caused by hazardous materials, drone flights, again, become well-plannable actions without involuntary commitments. Therefore, they lose their disaster-specific character and are similar to other civilian applications.

In case of nuclear accidents some of the most important information are that what strong the radioactivity, what is the affected area now and how fast spreading the radioactivity. In most cases we can assume the radioactivity is higher than the limit allowed for human. Thus any man-on-board operation is not just dangerous but even useless for human if there is alternative and similar effective solution. Observing and monitoring the radioactivity usually made by aerials which mean today not just man-on-board solution but also drone application.

\section{Earthquakes}

Earthquake is a typical disaster that is broken out without any pre-sign and causing not just seriously building damages but also many human die. The chance for survive of the people trapped in collapsed buildings depends mainly on the damage types of the affected buildings. Therefore, a rapid mapping of the affected area is very important not just for assessing the damages but even more to optimize sharing our rescue sources. Since the limited sources in disasters a small drone can be a good solution for rapid mapping.

After the rapid mapping injured buildings can be characterized by an international standard [3]. Based on the scaled ruins special rescue teams can optimize their work depending on the rate of assumed (measured) surviving holes. Since the chance for survive is drastically reduces in time the rapid mapping can effectively raise the rescued lives (Figure 3).
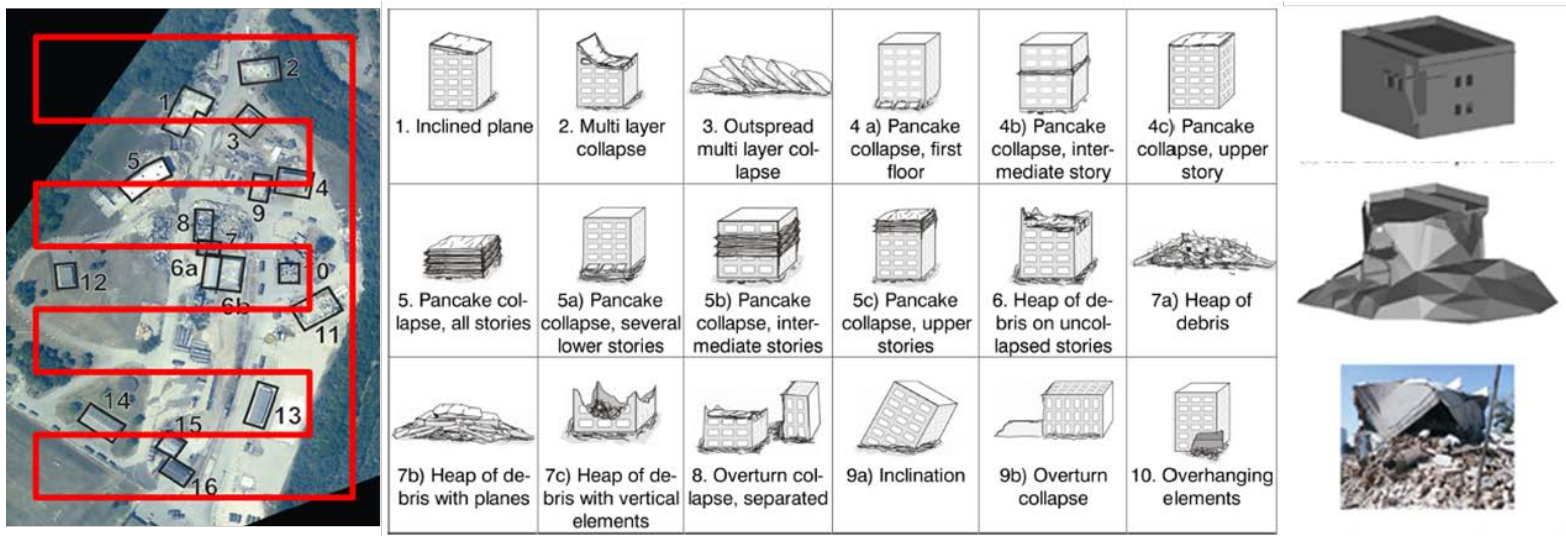

Figure 3. Mission planning above the affected area (left) [4], classification of collapsed building (middle) [3] and 3D modeling of the ruined buildings (right) [5]. 


\section{Floods}

Floods are a typical for a slowly developing disaster. In many times authority or disaster management headquarter have enough information to predict the scale and serious of this disaster. Against the slowly developing but in many times the country large affected area citizens can be trapped. Even if manned aerials can help in these situations demonstratively, drone activity around a limited area also can help for the management.

As pre-disaster activity, drone following the stream of rivers can control the state of dams. In case of any unusual recognition the responsible authority can react in time for the problem. This activity is very flexible; the flight patrol can be optimized depending on time or other work load. Since affected areas are usually oversized, managing floods by aerials is always suffered from limited sources. It means drone can support disaster management at local level. This task requires tactical or operational drone.

The stability of dams hangs on many conditions like the time it suffer from water press, how structure of dams built, what materials made of it. There is yet not enough information about it, however it can be supposed, with a procedure what is able to analyze the state of dam as airborne is help for managers. Knowing the state of dam managers can optimize the sources making the critic parts of dam stronger or in case of escalated problem can order the evacuation in time.

In case of unaccepted dam broken citizens can trapped in the flooded area. Even if they can find higher point in the area like sitting on the roof the evacuation is unavoidable. If the evacuation is possible by motorboats small drone in the hand of local or regional management can help to find trapped citizens.

Since floods are a slowly developing disaster drone can help for the management in many ways. With drone observation can predict how flooded the area, what buildings are in risk, where from and where to evacuate the citizens, etc. The essence of this application is the gap of aerials what means the missing of manned aerials but drone can offer as a satisfied solution (Figure 4).
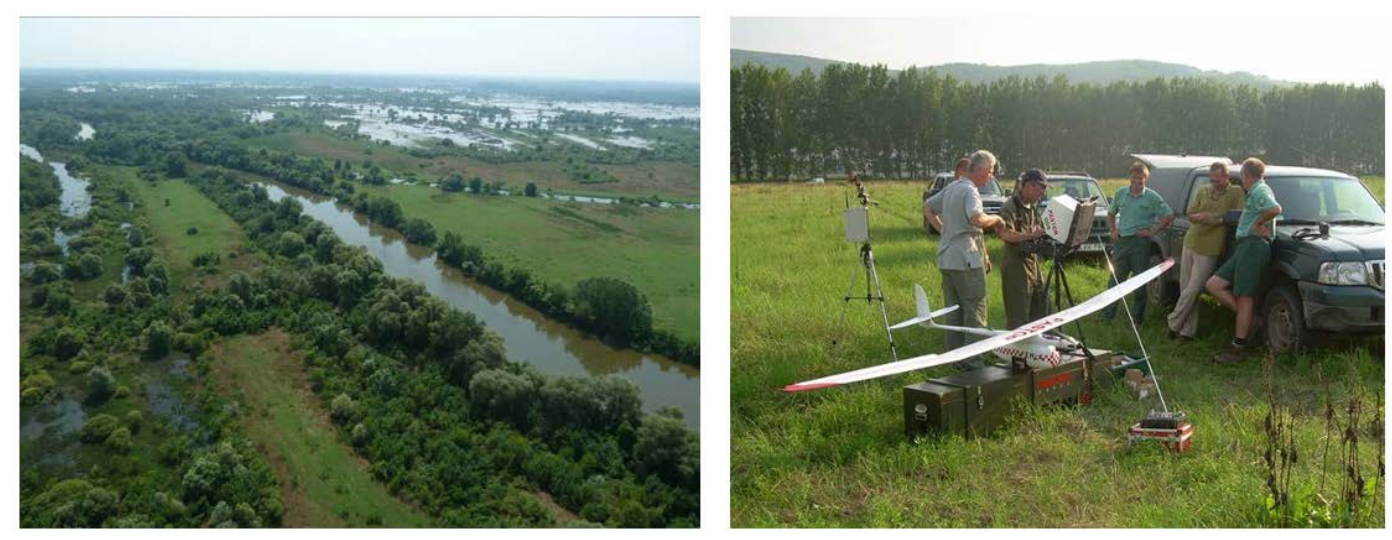

Figure 4. Drone mission during flood at the Aggtelek National Park, Hungary (2010). Source: author.

\section{Forest Fires}

The drone application supporting forest fire management is surely the most developed and practically demonstrated activity among all disasters [6]. Following the thematically separation of drone activity used above, logically drone can be used before fire for hot spot detection, during the intervention helping fire management with real time information and after suppression for post fire monitoring. The method of prescribed fire can be also in the focus of drone use as a special application for fire prevention [7].

Detecting hot spots by aerials earlier than reporting it by civilians is obviously helps fire managers limiting the damages fires cause [8]. Unfortunately the main reason why this method is not always used is the huge costs of aerials. If this procedure made by drone is cheaper solution than the traditional one (manned aircraft) means option of drone use is the better solution. Naturally this case assumes the similar professional efficiency of different methods.

During this task drone makes a patrol following the pre-programmed flight path and based on the real time video supply the staff in the control station can detect and check any hot spots (Figure 5). In case of real danger staff reports it to the fire service. 


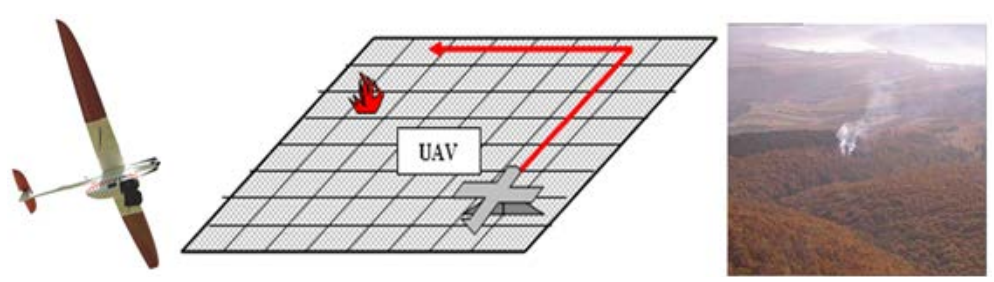

Figure 5. Fix wing drone with modelling its activity and a real hot spot detection in Szendro, Hungary (2006). Source: author.

There is no doubt, aerial patrol by drone can detect hot spots very quickly and able to give the first fire report to fire brigades. It can reduce the time of first attack but study says that based on economically this application can be effective just in special condition such as at extremely high Fire Weather Index and at geographically high articulated area. These criteria are explained detailed in other article [9].

In case of aerial reconnaissance before starting intervention is the situation totally different. Fire managers require some basic information about fires immediately and for this task a high qualified drone service is not applicable. The quickness of the information is much more important than the quality (ex. resolution of the video, photos) of that. Thus the simple but immediately ready for start drone is required for this type of task. Capability of this type of drone is limited. Fire manager needs objective information about the fire characteristic, fire intensity, speed of spreading fire, smoke emission, wind direction, etc. but very quickly. For this task a hand launch, by electric engine powered drone is required as a best solution.

During intervention, where aerial reconnaissance is required but manned aircraft is above price, drone could give also a cost effective solution. If the commander of fire-fighting operations is at the scene, he is too close to the fire to be able to manage it along with its environment. Quite literally, he cannot see the forest for the trees! As the extinction of forest fires is a protracted process in time, and since during that time the fire will continue to spread, the ability to manage a fire together with its environment is an indispensable precondition for the efficient extinguishing of a fire.

During intervention the drone use can be very effective because obtaining an overview of several hundred or even thousand hectares of forest allows intervention measures to be coordinated. Without air reconnaissance, coordination of measures can only be based on the information circulated between the commanders of individual units at various locations. But the assessment of the gravity of their individual situations by commanders located at various sites may be completely subjective and not made in relation to the other sites. Air reconnaissance helps to eliminate subjectivity in such judgements and to rank the individual sites in relation to the others.

At huge fires using manned aircraft for bombing water or just for supporting with information the reconnaissance is a normal procedure. Other side, small fires don't require aerial support; these are managed by traditional equipment. Between these extremes logically there is a sector, where fire size is larger than management could be suppress it successfully just with traditional equipment, but not enough large for asking manned aircraft for help. In this case the manned aircraft is economically obviously not effective, but a solution such as drone-what is cheaper than the use of manned aircraft—is already can (Figure 6).

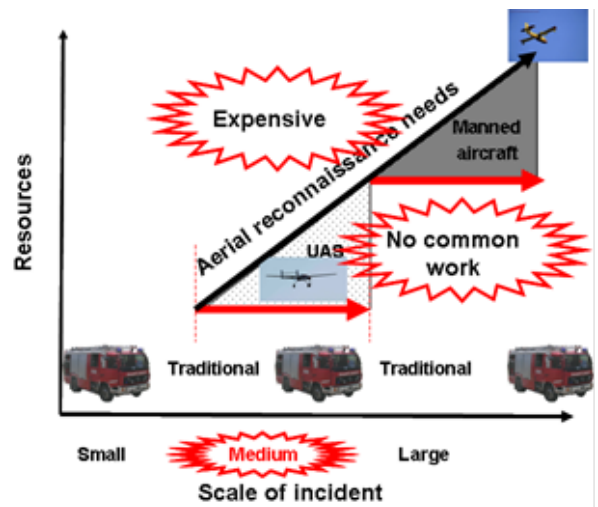

Figure 6. Efficiency of drone (UAS) application depends on fire size. Source: author. 


\section{References}

[1] Blyenburgh, P. (Edit. 2009/2010) UAS Yearbook, UAS—The Global Perspective, Paris, France.

[2] Molnar, A. (2014) UAV alkalmazások fejlesztése az Óbudai Egyetemen (Development of UAV Applications at Óbuda University), Presentation, AROP Project Conference, Szolnok, Hungary, 28. February 2014.

[3] Schweier, C. and Markus, M. (2006) Classification of Collapsed Buildings for Fast Damage and Loss Assessment. Bulletin of Earthquake Engineering, 4, 177-192. http://dx.doi.org/10.1007/s10518-006-9005-2

[4] Restas, A. (2012) Unmanned Aircraft System Applications: Firefighting. Introduction to Unmanned Systems: Air, Ground, See \& Space. In: LeMieux, J., Ed., Technologies and Commercial Applications, LCCN 2012954516.

[5] Rehor, M. (2007) Classification of Building Damage Based on Laser Scanning Data. The Photogrammetric Journal of Finland, 20, 54-63. http://foto.hut.fi/seura/julkaisut/pjf/pjf_e/pjf_e.html

[6] Restas, A. (2015) Thematic Division and Tactical Analysis of the UAS Application Supporting Forest fire Management. In: Viegas, X.D., Ed., Advances in Forest Fire Research, Coimbra, Portugal. http://dx.doi.org/10.14195/978-989-26-0884-6_172

[7] Restas, A. (2011) UAS Applications: From Aerial Patrol to Prescribed Fires. Wildfire 2011, The 5th International Wildland Fire Conference, Sun City, South Africa, 9-13 May 2011.

[8] Ambrosia, V., Hinkley, E., Brass, J.A., Buechel, S., Sullivan, D., Myers, J. and Schoenung, S. (2006) The Western States UAV Fire Mission. Eleventh Biennial USDA Forest Service, Remote Sensing Applications Conference RS-2006, New Remote Sensing Technologies for Resource Managers, Salt Lake City, Utah, USA, 24-28 April 2006.

[9] Restas, A, Hinkley, E.A. and Ambrosia, V.G. (2014) An Approach for Measuring the Effectiveness of Fire Detection Systems in Different Dimensions. Bolyai Szemle, 23, 283-296. 